\title{
Morbidity and Mortality Outcome in Late Preterm Neonates at a Tertiary Care Hospital
}

\author{
Amin $T^{1}$, Nur $\mathrm{AN}^{2}$
}

\begin{abstract}
Introduction: The morbidity and mortality in late preterm neonates is higher than term neonates. The main reason is the relative physical and neurologic immaturity, though there is no significant difference in the weight or the size of the two groups.
\end{abstract}

Objective: The study was conducted to compare the early neonatal morbidity and mortality (within first 7 days of life) in late preterm infants (34-36 6/7 weeks) with those in term neonates (37-41 6/7 weeks).

Materials and Methods: This was a prospective study conducted from 01 January 2015 to 30 June 2015 in the department of Neonatology at a tertiary hospital.

Results: Total 100 neonates were included in the study; fifty neonates in each group. Late preterm infants had significantly higher morbidity due to any cause, e.g. respiratory morbidity $(p<0.05)$, jaundice $(p<0.05)$, hypoglycemia $(p<0.05)$, sepsis $(p<0.05)$ and perinatal asphyxia $(p<0.05)$. Early neonatal mortality in late preterm neonates was significantly higher than term neonates $(p<0.05)$.

Conclusion: Late preterm neonates are at high risk for morbidity and mortality as compared to term neonates.

Key-words: preterm neonates, morbidity, mortality.

\section{Introduction}

Preterm birth rates are on the rise all over the world and continue to be the most important determinant of neonatal morbidity and mortality ${ }^{1}$. Preterm delivery can occur spontaneously or by obstetric intervention and may or may not be a result of pregnancy complications or preexisting maternal medical conditions ${ }^{2}$. In either case, infants who are born preterm are at an increased risk for newborn morbidity and mortality ${ }^{3}$. The morbidity and mortality pattern in late preterm infants is higher than term infants (gestational age $\geq$ 37 weeks) $)^{4}$. The main reason behind that is the relative physiologic and metabolic immaturity, though there is no significant difference in the weight or the size of the two groups ${ }^{5}$. The late preterm infants are at twice to thrice increased risk of morbidities like hypoglycemia, poor feeding, jaundice, infection and re-admission rates after initial hospital discharge ${ }^{6}$. The infant mortality rate during first year of life for late preterm infants is on an average four-fold higher than that for term infants ${ }^{7}$.

Late preterm infants- The American Academy of Pediatrics (AAP), American College of Obstetrics and Gynecology (ACOG) and National Center for Health Statistics (NCHS) define late preterm birth as the delivery of an infant from 34 weeks to 36 weeks and 6 days of gestation (i.e., 239 to 259 days after the first day of the LMP) $)^{8}$. They account for $9.1 \%$ of all births and three-quarter of all preterm births ${ }^{9}$.

Apnea occurs more frequently among late preterm infants than term infants ${ }^{10}$. The incidence of apnea in late preterm infants is reported to be between $4 \%$ and $7 \%$ compared with $1 \%$ to $2 \%$ at term ${ }^{11}$. Immature liver glycogenolysis, hormonal dysregulation and inefficient hepatic glycogenesis and ketogenesis predispose preterm neonates for developing symptomatic hypoglycemia ${ }^{12}$. Also, late preterm infants have increased chances of developing hyperbilirubinemia because feeding difficulties predispose them to an increase in enterohepatic circulation, decreased stool frequency and dehydration ${ }^{13}$. Late preterm infants are also more vulnerable to develop various respiratory morbidities including transient tachypnea of the newborn, respiratory distress syndrome, pneumonia and pulmonary hypertension ${ }^{14}$. Most common factor responsible for late preterm birth is preterm labor $(45 \%)^{15}$. Late preterm neonates have increased risk of

1. Dr Tahsinul Amin, MBBS, MD (Neonatology), Associate Professor of Neonatology, Sher-e-Bangla Medical College, Barisal 2. Dr Ayesha Najma Nur, MBBS, Department of Obs and Gynae, BSMMU, Dhaka. 
mortality and morbidity. However, late preterm infants are more likely to develop problems such as respiratory distress, apnea, feeding intolerance, hyperbilirubinemia hypoglycemia and hypothermia ${ }^{16}$. Moreover, the prevalence of these problems may be different in each country ${ }^{17}$ Therefore, determining the risk factors in these infants leads to more comprehensive preventive and treatment strategies $^{18}$. Late preterm infants who have potentially higher risk for morbidity and hospitalization require closer monitoring and follow-up ${ }^{19}$.

\section{Materials and Methods}

This prospective cohort study was conducted in the Neonatal ward at Sher-E-Bangla Medical College, Barisal in Bangladesh from 01 January 2015 to 30 June 2015. The objective of the study was to identify early neonatal morbidity and mortality (within first 7 days of life) in late preterm infants (34-36, 6/7 weeks) in comparison to those in term neonates. Inclusion criteria were both the late preterm neonates (34-36, 6/7 week gestation) and term neonates (37-41, 6/7 week gestation) and exclusion criteria were major congenital anomalies and clinically identifiable chromosomal syndromes. Gestational age was assessed by maternal last menstrual period (LMP) and New Ballard score. All infants enrolled in the study were followed up for first seven days of life for any morbidity and mortality. The common morbidity e.g. apnea, hypoglycemia, jaundice, sepsis, perinatal asphyxia, respiratory distress syndrome (RDS) were evaluated and mortality were compared between the two study groups. All data collected were analyzed using SPSS software version 12. Chi-square test or Fishers exact test and student $t$ test were used for statistical analysis. The $p$-value $<0.05$ was considered significant.

\section{Results}

The study was conducted from 01 January 2015 to 30 June 2015. The study groups included a total of 100 live born neonates; fifty were late preterm neonates and another 50 were term neonates, who were compared for morbidity and mortality; gestational age, birth weight and male/female ratio in both groups were comparable i.e. ( $p$ value $>0.05$ ). Table-I shows the baseline variables of the study population.

Table-I: Baseline Variables of the study population

\begin{tabular}{|l|l|r|r|r|}
\hline \multicolumn{2}{|c|}{ Variable } & $\begin{array}{r}\text { Late preterm } \\
(\mathbf{n = 5 0})\end{array}$ & $\begin{array}{r}\text { Term } \\
(\mathbf{n}=\mathbf{5 0})\end{array}$ & $\begin{array}{c}\mathbf{P} \\
\text { value }\end{array}$ \\
\hline Gestation (wks) Mean (SD) & $35.8 \pm 0.2$ & $37.2 \pm 0.2$ & $>0.05$ \\
\hline \multicolumn{2}{|l|}{ Birth weight (gm) Mean (SD) } & $2220 \pm 48$ & $2610 \pm 24$ & $>0.05$ \\
\hline \multirow{2}{*}{ Sex } & Male & $52 \%$ & $51 \%$ & \multirow{2}{*}{$>0.05$} \\
\cline { 2 - 4 } & Female & $48 \%$ & $49 \%$ & \\
\hline \multirow{2}{*}{$\begin{array}{l}\text { Mode of } \\
\text { delivery }\end{array}$} & Vaginal & $24 \%$ & $28 \%$ & \multirow{2}{*}{$>0.05$} \\
\cline { 2 - 4 } & Cesarean & $76 \%$ & $72 \%$ & \\
\hline
\end{tabular}

Both the study groups were compared for various morbidities e.g. apnea, respiratory distress, feed intolerance, hypoglycemia, hypothermia, hyperbilirubinemia, sepsis, Necrotising enterocolitis (NEC) and perinatal asphyxia. Late preterm neonates had statistically more significant complications than the term neonates, i.e. $p$ value $<0.05$. The results are given below in Table-II.

Table-II: Morbidity outcome of late preterm neonates and the term neonates

\begin{tabular}{|l|c|c|c|c|c|}
\hline \multirow{2}{*}{ Morbidity } & \multicolumn{2}{|c|}{$\begin{array}{c}\text { Late preterm } \\
\text { Neonates }\end{array}$} & \multicolumn{2}{c|}{$\begin{array}{c}\text { Term } \\
\text { Neonates }\end{array}$} & $\begin{array}{c}\text { P } \\
\text { value }\end{array}$ \\
\cline { 2 - 6 } & $\mathrm{n}(50)$ & $\%$ & $\mathrm{n}(50)$ & $\%$ & \\
\hline Apnea & 24 & 48 & 3 & 6 & $<0.05$ \\
\hline Respiratory distress & 12 & 24 & 2 & 4 & $<0.05$ \\
\hline Feed intolerance & 18 & 36 & 4 & 8 & $<0.05$ \\
\hline Hypoglycemia & 14 & 28 & 2 & 4 & $<0.05$ \\
\hline Hypothermia & 8 & 16 & 0 & 0 & $<0.05$ \\
\hline Hyperbilirubinemia & 22 & 44 & 5 & 10 & $<0.05$ \\
\hline Sepsis & 25 & 50 & 7 & 14 & $<0.05$ \\
\hline NEC & 3 & 6 & 0 & 0 & $<0.05$ \\
\hline Perinatal asphyxia & 16 & 32 & 5 & 10 & $<0.05$ \\
\hline
\end{tabular}

Over all morbidity between late preterm neonates and term neonates was statistically significant, $76 \%$ late preterm infants had morbidities compared with $28 \%$ term infants as shown in Table-III.

Table-III: Morbidity outcome of late preterm neonates and term neonates

\begin{tabular}{|l|c|c|c|c|c|}
\hline Morbidity & \multicolumn{2}{|c|}{$\begin{array}{c}\text { Late preterm } \\
\text { neonates }\end{array}$} & \multicolumn{2}{c|}{$\begin{array}{c}\text { Term } \\
\text { neonates }\end{array}$} & $\begin{array}{c}\text { P } \\
\text { value }\end{array}$ \\
\cline { 2 - 5 } & $\mathrm{n}(50)$ & $\%$ & $\mathrm{n}(50)$ & $\%$ & \multirow{2}{*}{$<0.05$} \\
\hline Present & 38 & 76 & 14 & 28 & \\
\hline Absent & 12 & 24 & 36 & 72 & \\
\hline
\end{tabular}

Mortality outcome was compared between the two study groups; mortality was statistically more significant in late preterm neonates $(28 \%)$ than the term neonate $(6 \%)$, i.e. $p$ value $<0.05$

Table-IV: Mortality outcome of late preterm neonates and the term neonates

\begin{tabular}{|c|c|c|c|c|c|}
\hline \multirow{2}{*}{ Mortality } & \multicolumn{2}{|c|}{$\begin{array}{c}\text { Late preterm } \\
\text { neonates }\end{array}$} & \multicolumn{2}{c|}{$\begin{array}{c}\text { Term } \\
\text { neonates }\end{array}$} & $\begin{array}{c}\text { P } \\
\text { value }\end{array}$ \\
\cline { 2 - 5 } & $\mathrm{n}(50)$ & $\%$ & $\mathrm{n}(50)$ & $\%$ & \\
\hline Alive & 36 & 72 & 47 & 94 & $<0.05$ \\
\hline Death & 14 & 28 & 3 & 6 & \\
\hline
\end{tabular}

\section{Discussion}

All infants enrolled in study were followed up for first seven days of life for any morbidity and mortality. The common morbidity e.g. apnea, hypoglycemia, jaundice, sepsis, perinatal asphyxia, respiratory distress 
syndrome (RDS) were evaluated and mortality were compared between the two study groups. Overall morbidity was found significantly higher in late preterm neonates $(76 \%)$ as compared to term neonates $(28 \%)$ ( $p$ value $<0.05)$. Similar result was found by Srinivasmurki et $\mathrm{al}^{4}$ In this study, late preterm neonates had significantly higher mortality than term neonates (28\% vs $6 \%$, p value <0.05); similar results were found by Young et $\mathrm{al}^{12}$ and Esobar et al $^{16}$ Late preterm neonates in this study had more complications compared to term neonates. Sepsis was the most frequent morbidity, $50 \%$ in late preterm neonates as compared with $14 \%$ in term neonates, which was statistically significant ( $p$ value $<0.05$ ); similar result was found in the previous study $^{20}$. Besides neonatal sepsis, other neonatal complications were statistically more significant in late preterm neonates than term neonates; apnea (48\% vs $6 \%, p<0.05)$, respiratory distress $(24 \%$ vs $4 \%, p<0.05)$, feed intolerance (36\% vs $8 \%, p<0.05)$, hypoglycemia $(28 \%$ vs $4 \%, p<0.05)$, hypothermia (16\% vs $0 \%, p<0.05)$, hyperbilirubinemia (44\% vs $10 \%, p<0.05)$, NEC (6\% vs $0 \%, p<0.05)$ and perinatal asphyxia $(32 \%$ vs $10 \%, p<0.05)$. Wang et

${ }^{21}$ did a study in which they found jaundice in $54.4 \%$ late preterm neonates and $37.9 \%$ term neonates (OR 1.95, 95\% Cl (1.04-3.67), p-value $<0.027$. Due to relative deficiency of uridinediphosphoglucuronate-glucuronosyltransferase (UDPGT), there is more chance of hyperbilirubinaemia among late-preterm infants than term infants ${ }^{22}$. Also, late-preterm infants have increased chances of developing hyperbilirubinaemia because feeding difficulties predispose them to an increase in enterohepatic circulation, decreased stool frequency and dehydration ${ }^{23,24}$.

Araújo BF, Zatti $\mathrm{H}$ et al, found that late-preterms were statistically more likely to be subjected to hypoglycemia as compared to term neonates ${ }^{3}$. Similar result was found in this study where hypoglycemia in late preterm infants was significantly higher than term infants. Preterm infants are at increased risk of developing hypoglycemia after birth, because they have immature hepatic glycogenolysis and adipose tissue lipolysis, hormonal dysregulation and deficient hepatic gluconeogenesis and ketogenesis ${ }^{25}$. Statistically respiratory morbidities were found significantly higher in late preterm neonates as compared to term neonates ( $p$-value <0.05). Hendricks-Muñoz KD et al found Respiratory Distress Syndrome (RDS) in $9 \%$,
4\%, 3\%, in 34-week, 35-week, 36-week as compared to $0.7 \%, 0.2 \%$ and $0 \%$ in 37 -week, 38 to 39 week, and 40 -week gestational age neonates $(p<0.001)^{1}$. In this study late preterm neonates had perinatal asphyxia and NEC significantly higher as compared to term neonates. Similar results were found in other studies $^{26,27}$

In this study, death occurred in $28 \%$ of late preterm neonates as compared to $6 \%$ in term neonates. Statistically, mortality was found significantly higher in late preterm neonates as compared to term neonates $(p<0.05)$. Celik $\mathrm{IH}$ et $\mathrm{al}^{2}$ also found mortality in late preterm significantly higher as compared to term neonates $(p<0.001)$.

\section{Conclusion}

This study revealed that late-preterm neonates have significantly higher risk of morbidity and mortality compared with term newborns. Further research is needed to find out the greater risk and early recognition, greater care and optimal management can reduce morbidity and mortality in late preterm neonates.

\section{References}

1. Mally PV, Hendricks-Muñoz KD, Bailey S. Incidence and etiology of late preterm admissions to the neonatal intensive care unit and its associated respiratory morbidities when compared to term infants. Am J Perinatol 2013; 30(5):425-31.

2. Celik IH, Demirel G, Canpolat FE et al. A common problem for neonatal intensive care units: Late preterm infants, a prospective study with term controls in a large perinatal center. J Matern Fetal Neonatal Med 2013; 26(5):459-62.

3. Araújo BF, Zatti H, Madi JM et al. Analysis of neonatal morbidity and mortality in late-preterm newborn infants. J Paediatr (Rio.J) 2012; 88(3):259-66.

4. Jaiswal A, Murki S, Gaddam P et al. Early neonatal morbidities in late preterm infants From Fernandez hospital, Hyderabad. Indian Paediatr 2011; 48:607-11.

5. Picone S, Paolillo P. Neonatal outcomes in a population of late-preterm infants. J Matern Fetal Neonatal Med 2010; 23(S3): 116-20.

6. Mateus J, Fox K, Jain S et al. Pretermpremature rupture of membranes: Clinical outcomes of late-preterminfants. ClinPediatr (Phila)2010; 49:60-5.

7. Melamed N, Klinger G, Tenenbaum-Gavish K et al. Shortterm neonatal outcome in low-risk, spontaneous, singleton, late preterm deliveries. ObstetGynecol 2009; 114:253-60. 
8. Shapiro-Mendoza CK, Tomashek KM, Kotelchuck M et al. Effect of late-preterm birth and maternal medical conditions on newborn morbidity risk. Pediatrics 2008; 121:223-32.

9. Santos IS, Matijasevich A, Silveira MF et al. Associated factors and consequences of late preterm births: Results from the 2004 Pelotas birth cohort. Paediatr Perinat Epidemiol 2008; 22(4):350-59.

10. McIntire DD, Leveno KJ. Neonatal mortality and morbidity rates in late preterm births compared with births at term. Obstet Gynaecol 2008; 111(1):35-41.

11. American Academy of Paediatrics. Guidelines for Perinatal Care. 5th ed. Elk Grove Village, IL: American Academy of Paediatrics; 2005. American College of Obstetricians and Gynaecologists.

12. Young PC, Glasgow TS, Li X et al. Mortality of late-preterm (near-term) newborns in Utah. Pediatrics 2007; 119:659-65.

13. Tomashek KM, Shapiro-Mendoza CK, Davidoff MJ et al. Differences in mortality between late-preterm and term singleton infants in the United States,1995-2002. J Paediatr 2007; 151(5): 450-6.

14. Pulver LS, Guest-Warnick G, Stoddard GJ et al. Weight for gestational age affects the mortality of late preterm infants. Paediatrics 2009; (6):123.

15. Hamilton BE, Martin JA, Ventura SJ. Births: Preliminary data for 2007. Natl Vital Stat Rep 2009; 57(12):1-23.

16. Escobar GJ, Clark RH, Greene JD. Short-term outcomes of infants born at 35 and 36 weeks gestation: we need to ask more questions. SeminPerinatol 2006; 30(1):28-33.

17. Davidoff MJ, Dias T, Damus K et al. Changes in the gestational age distribution among U.S. singleton births: impact on rates of late preterm birth, 1992-2002. Semin Perinatol 2006; 30:313.
18. Hankins GD, Longo M. The role of stillbirth prevention and late preterm (near-term) births. Semin Perinatol 2006; 30:20-3.

19. Sibai BM. Pre-eclampsia as a cause of preterm and late preterm (near-term) births. Semin Perinatol 2006; 30:16-9.

20. Clark RH. The epidemiology of respiratory failure in neonates born at an estimated gestational age of 34 weeks or more. J Perinatol 2005; 25(4):251-7.

21. Wang ML, Dorer DJ, Fleming MP et al. Clinical outcomes of near-term infants. Paediatrics 2004; 114:372.

22. Sarici SU, Serdar MA, Korkmaz A et al. Incidence, course, and prediction of hyperbilirubinaemia in near-term and term newborns. Paediatrics 2004; 113:775-80.

23. Escobar GJ, McCormick MC, Zupancic JA et al. Unstudied infants: Outcomes of moderately premature infants in the NICU. Paediatric Research 2004; 55:505A.

24. Gilbert WM, Nesbitt TS, Danielsen B. The cost of prematurity: quantification by gestational age and birth weight. ObstetGynaecol 2003; 102:488-92.

25. Kramer MS, Demissie K, Yang $\mathrm{H}$ et al. The contribution of mild and moderate preterm birth to infant mortality. Fetal and Infant Health Study Group of the Canadian Perinatal Surveillance System. JAMA 2000; 284:843.

26. Moutquin JM. Classification and heterogeneity of preterm birth. BJOG 2003; 110:30-3.

27. Linhart $\mathrm{Y}$, Bashiri A, Maymon $\mathrm{E}$ et al. Congenital anomalies are an independent risk factor for neonatal morbidity and perinatal mortality in preterm birth. Eur $\mathrm{J}$ ObstetGynaecolReprod Biol 2000; 90:43-9. 